\title{
Susceptibility of the human LNCaP prostate cancer cells to the apoptotic effect of marina crystal minerals (MCM) in vitro
}

\author{
MAMDOOH GHONEUM $^{1}$ and SASTRY GOLLAPUDI ${ }^{2}$ \\ ${ }^{1}$ Department of Otolaryngology, Charles Drew University of Medicine and Science, Los Angeles, CA 90059; \\ ${ }^{2}$ University of California, Irvine, Division of Basic and Clinical Immunology, Irvine, CA 92697, USA
}

Received February 5, 2009; Accepted March 26, 2009

DOI: 10.3892/or_00000419

\begin{abstract}
Prostate cancer is one of the most frequent cancers among men in the United States. In the current study, we examined the susceptibility of the human LNCaP prostate cancer cells to the apoptotic effect of marina crystal minerals (MCM), a crystallized mixture of minerals and trace elements from sea water, in vitro. Cancer cells were cultured with MCM at different concentrations $(0-1000 \mu \mathrm{g} / \mathrm{ml})$. At day 3, MCM exhibited a marked apoptotic effect on LNCaP cells as measured by propidium iodide (PI) and Giemsastained cytospin preparations. The apoptotic effect was dosedependent: a 2-fold increase in the level of apoptosis over the control cells was observed at low concentrations of $50 \mu \mathrm{g} / \mathrm{ml}$, maximial (3-fold) at a concentration of 500-1000 $\mu \mathrm{g} / \mathrm{ml}$. The mechanism by which MCM induces apoptosis was examined. Flow cytometery analysis demonstrated that mitochondrial membrane potential was significantly decreased post-treatment with MCM at low concentrations of $100 \mu \mathrm{g} / \mathrm{ml}$. In addition, Western blot analysis showed that the level of anti-apoptotic molecule Bcl-2 in LNCaP cells decreased upon treatment with MCM. We conclude that MCM has an apoptotic effect toward human prostate cancer cells, which may suggest its broader potential as an innovative, non-toxic anti-cancer agent.
\end{abstract}

\section{Introduction}

Prostate cancer is the most common non-cutaneous cancer among males. Prostate-specific antigen (PSA) and digital rectal examination (DRE) are the 2 components necessary for a modern screening program. While prostate cancer can be a slow-growing cancer, thousands of men die of the disease each year. According to recent figures from the American Cancer

Correspondence to: Dr Mamdooh Ghoneum, Charles Drew University of Medicine and Science, Department of Otolaryngology, 1621 E. 120th Street, Los Angeles, CA 90059, USA

E-mail: mghoneum@ucla.edu

Key words: marina crystal minerals, LNCaP, apoptosis, Bcl-2
Society, 220,900 new cases were diagnosed in 2003 and 28,900 men were predicted to die of prostate cancer. Prostate cancer is rarely diagnosed in men younger than 40 years and it is uncommon in men younger than 50 years. Prostate cancer is also found during autopsies performed following other causes of death. The rate of this latent- or autopsydiagnosed cancer is much greater than that of clinical cancer. In fact, it may be as high as $80 \%$ by age 80 years. In addition, genetic studies suggest that a strong familial predisposition may be responsible for as many as $5-10 \%$ of prostate cancer cases $(1,2)$. Most prostate cancers are adenocarcinomas (95\%). Prior to metastasis, oncologists mainly rely on surgery, chemotherapy and radiation therapy for cancer treatment of prostate cancers. The destruction of cells by chemotherapy and radiation therapy is indiscriminate with serious side effects. In addition to being toxic, both chemotherapy and radiation therapy are also immune-suppressive, mutagenic and carcinogenic (3-6). Hormone therapy is also commonly used to treat prostate cancer. Most clinical trials to date have evaluated flutamide or nilutamide for the treatment of advanced prostate cancer. Results showed that these drugs resulted in a survival increase of only $8 \%$ at 5 years (7).

In the field of prostate cancer therapeutics, it is known that some cancers respond well to specific chemotherapy while others do not. Age and health status play a significant role in determining treatment regimens and the toxic effect of chemotherapy may exclude this treatment as an option for some patients. For prostate cancer that metastasizes, there is no cure and treatment is mostly palliative. Such considerations emphasize the need to identify new compounds as possible therapeutic agents for human prostate cancer with minimal or no side effects.

Our recent studies show that marina crystal minerals (MCM), a crystallized mixture of minerals and trace elements from sea water, has an apoptotic effect against human metastatic breast cancer cells (8) and an overall immune modulatory effect (9). In the current study, we investigated whether MCM extends its apoptotic effect also against prostate cancer cells. Results demonstrated that MCM inhibits the growth of prostate cancer cells (LNCaP) by a mechanism that involves down-regulation of the antiapoptotic molecule Bcl-2. This observation coupled with MCM's ability to enhance human NK cell activity suggests that MCM could be used as a new potent anti-cancer agent. 


\section{Materials and methods}

Tumor cell line. Human prostate cancer cells (LNCaP) were used in the present study. Cells were purchased from American Type Culture Collection (ATCC), Manassas VA, USA. Tumor cells were maintained in our laboratory by serial passage at a starting density of $3 \times 10^{5}$ cells $/ \mathrm{ml}$ in complete medium.

Complete medium (CM). CM consists of RPMI-1640 supplemented with $10 \mathrm{mg} / \mathrm{ml}$ glutamine, $10 \%$ heat inactivated fetal calf serum and 100 units penicillin and $100 \mu \mathrm{g} / \mathrm{ml}$ streptomycin.

Marina crystal minerals (MCM). MCM is a crystallized mixture of minerals, trace elements and other active ingredients from sea water, which were originally separated from sodium chloride. MCM was dissolved in $\mathrm{CM}$ at various concentrations $(0-1000 \mu \mathrm{g} / \mathrm{ml})$. MCM was provided by the Foundation for Basic Research Institute of Oncology, Japan.

Growth of monolayer LNCaP in 8-well plates. A model assay system previously developed by us (10) was used to examine apoptosis of monolayer LNCaP following culture with MCM. This system allows us to examine apoptosis of adherent cancer cells. Cancer cells were allowed to grow in 8-well plates (26x33 mm each) (LUX Scientific Corp., Thousand Oaks, CA, USA) with a cover glass placed at the bottom of each well. Cancer cells $\left(1 \times 10^{5}\right.$ cells $\left./ \mathrm{ml}\right)$ were pipetted into each well and allowed to adhere. After $2 \mathrm{~h}$, the cells were washed once with $1 \mathrm{ml} \mathrm{CM}$. To each well, MCM $(500 \mu \mathrm{g} / \mathrm{ml})$ was added and plates were incubated at $37^{\circ} \mathrm{C}$ and $5 \% \mathrm{CO}_{2}$. At three days post-treatment, adherent cells were examined as follows: Cover glasses containing adherent cells were carefully removed, air-dried, and mounted on slides. Preparations were fixed in 100\% methanol, air-dried, stained with $4 \%$ Giemsa stain (Sigma-Aldrich Corp., St. Louis, MO, USA) for 15 min and examined for percent apoptosis using a light microscope fitted with a $100 \mathrm{X}$ oil immersion objective (Nikon, Tokyo, Japan).

Apoptosis studies. Detection of cancer cell viability using propidium iodide (PI). Cancer cells (LNCaP) were cultured in the presence or absence of MCM $(0-1000 \mu \mathrm{g} / \mathrm{ml})$ for 3 days and the percentage of dead cancer cells was examined by the propidium iodide (PI) technique using a FACScan flow cytometer. In this technique, dead cells pick up PI and fluoresce (11). Briefly, PI was added to the cells $\left(1 \times 10^{6} / \mathrm{ml}\right)$ to give a final PI concentration of $(50 \mu \mathrm{g} / \mathrm{ml})$. The cells were stained for $30 \mathrm{~min}$ at room temperature in the dark and analyzed by FACScan flow cytometery (Becton-Dickinson, San Jose, CA, USA).

Detection of mitochondrial membrane potential (MMP). Variations of the MMP during apoptosis were studied using tetramethylrhodamine ethyl ester (TMRE, Molecular Probes, Eugene, OR, USA). Briefly, after treatment with MCM $(100-500 \mu \mathrm{g} / \mathrm{ml})$ for $24 \mathrm{~h}, 5 \times 10^{5}$ cells $/ \mathrm{ml}$ were incubated with $50 \mathrm{nM}$ TMRE for $30 \mathrm{~min}$ at $37^{\circ} \mathrm{C}$. The cells were washed with PBS and analyzed with FACScan flow cytometry (BectonDickinson).
Western blot analysis. The expression of Bcl-2 was determined using Western blot analysis. Cancer cells were cultured with MCM (0-1000 $\mu \mathrm{g} / \mathrm{ml})$ for 3 days. The cells were harvested, washed with cold PBS [10 mmol/l (pH 7.4)], and lysed with ice-cold lysis buffer [50 mmol/1 Tris- $\mathrm{HCl}, 150 \mathrm{mmol} / \mathrm{l} \mathrm{NaCl}$, $1 \mathrm{mmol} / \mathrm{l} \mathrm{EGTA,} 1 \mathrm{mmol} / \mathrm{l} \mathrm{EDTA}, 20 \mathrm{mmol} / \mathrm{l} \mathrm{NaF}, 100 \mathrm{mmol} / \mathrm{l}$ $\mathrm{Na}_{3} \mathrm{VO}_{4}, 1 \% \mathrm{NP} 40,1 \mathrm{mmol} / \mathrm{l}$ phenyl-methylsulfonyl fluoride, $10 \mu \mathrm{g} / \mathrm{ml}$ aprotinin, and $10 \mu \mathrm{g} / \mathrm{ml}$ leupeptin ( $\mathrm{pH}$ 7.4)] for 30 min and centrifuged at $14,000 \mathrm{x} \mathrm{g}$ for $20 \mathrm{~min}$ at $4^{\circ} \mathrm{C}$, as detailed previously (12). The supernatant was collected and used immediately. The protein concentration was determined using a BCA protein assay kit (Pierce, Rockford, IL, USA) according to the manufacturer's protocol. The cell lysate $(75 \mu \mathrm{g})$ in lysis buffer were subjected to Western blot analysis by $4-12 \%$ SDS polyacrylamide gel electrophoresis using 1:500 anti-Bcl-2 antibody (BD Biosciences, San Jose, CA, USA) as primary antibody. The washed polyvinylidene fluoride (PVDF) membranes were incubated with a 1:2000 dilution of monoclonal secondary antibodies. The immunoreactive bands were visualized by using an ECL Western blotting kit (Amersham, Buckinghamshire, UK). To verify equal protein loading and transfer, the blots were stripped and re-probed with a rabbit anti- $\beta$ actin polyclonal antibody. Thereafter the same protocol was followed as detailed above.

\section{Results}

Flow cytometery analysis. To determine whether MCM exerts an apoptotic effect against human prostate cancer, LNCaP cancer cells were cultured with MCM at various concentrations $(0-1000 \mu \mathrm{g} / \mathrm{ml})$ for 3 days. The apoptotic effect of MCM was then analyzed using flow cytometery. Results showed that LNCaP cells demonstrated a remarkable response to the apoptotic effect of MCM in a dose-dependent fashion (Fig. 1). A significant induction of apoptosis (a 2-fold increase over the control cells) was detected at low concentrations of MCM $(50 \mu \mathrm{g} / \mathrm{ml})$. The apoptotic effect of MCM was maximal (3-fold) at a concentration of $500 \mu \mathrm{g} / \mathrm{ml}$ and was maintained at the same level at higher concentrations of $1000 \mu \mathrm{g} / \mathrm{ml}$.

Detection of apoptotic cells by morphological analysis. Apoptosis is morphologically defined by cell shrinkage, membrane blebbing and chromatin condensation. These criteria were used to identify apoptotic LNCaP cells in cytospin preparations stained with Giemsa. Cancer cells were treated for 3 days with MCM (250 and $500 \mu \mathrm{g} / \mathrm{ml}$ ) and adherent cells were analyzed for percent apoptosis using microscopy of Giemsa-stained preparations. Results in Fig. 2 showed a significantly increased level of apoptosis in cancer cells following treatment with MCM as compared with control untreated cells. MCM treatment at concentrations of 250 and $500 \mu \mathrm{g} / \mathrm{ml}$ demonstrated 2-fold and 3-fold increase over control, untreated cells $(\mathrm{P}<0.01)$.

Effect of MCM on mitochondrial membrane potential. Treatment of LNCaP cells with MCM for $24 \mathrm{~h}$ resulted in a decrease in the mitochondrial polarization. Data in Fig. 3 demonstrate that the effect was significant at a concentration 

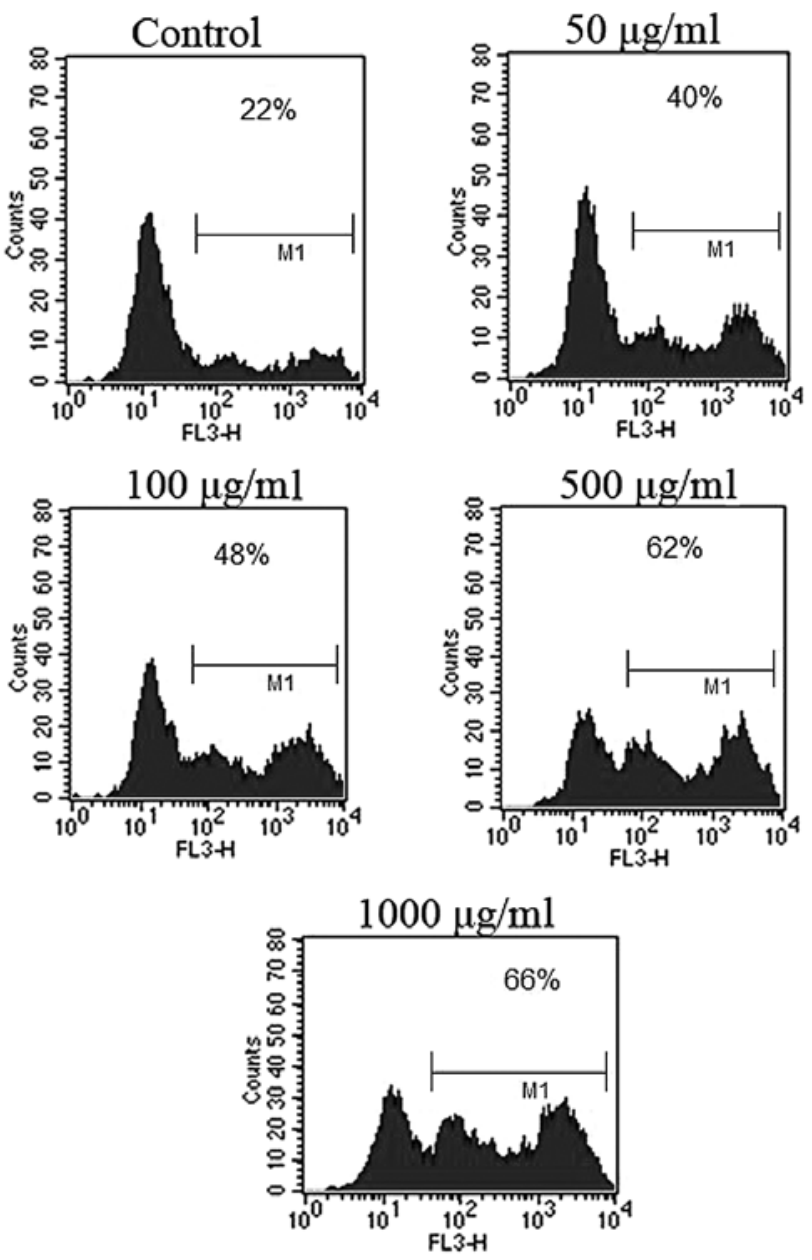

Figure 1. Effect of MCM on LNCaP tumor cell apoptosis examined by flow cytometry. Tumor cells were cultured with MCM at different concentrations $(0-1000 \mu \mathrm{g} / \mathrm{ml})$ for 3 days. Cell apoptosis was examined by using propidium iodide (PI) and flow cytometry. Data shown are representative of three independent experiments.

of $100 \mu \mathrm{g} / \mathrm{ml} \mathrm{MCM}$ and was maintained at higher concentrations of $250-500 \mu \mathrm{g} / \mathrm{ml}$.

Effect of MCM on Bcl-2 protein levels. The protein expression of the anti-apoptotic molecule Bcl-2 was examined in $\mathrm{LNCaP}$ cells post-treatment with MCM $(0-1000 \mu \mathrm{g} / \mathrm{ml})$. Fig. 4 depicts the results of Western blot analysis, showing that treatment of cancer cells with MCM for 3 days resulted in significant down-regulation of the anti-apoptotic protein Bcl-2 $(\mathrm{P}<0.001)$ as compared to control untreated cells.

\section{Discussion}

The results presented have demonstrated that marina crystal minerals (MCM) can be used as a potent apoptotic agent for the human prostate cancer cell line $\mathrm{LNCaP}$ in vitro. The mechanism by which MCM induces apoptosis in LNCaP cells was examined. Results demonstrated that the mitochondrial membrane potential (MMP) was significantly decreased following treatment with low concentrations $(100-500 \mu \mathrm{g} / \mathrm{ml})$ of MCM. Maintenance of the MMP is tightly regulated and essential for normal cell function. Permeabilization of the mitochondrial inner membrane leads to

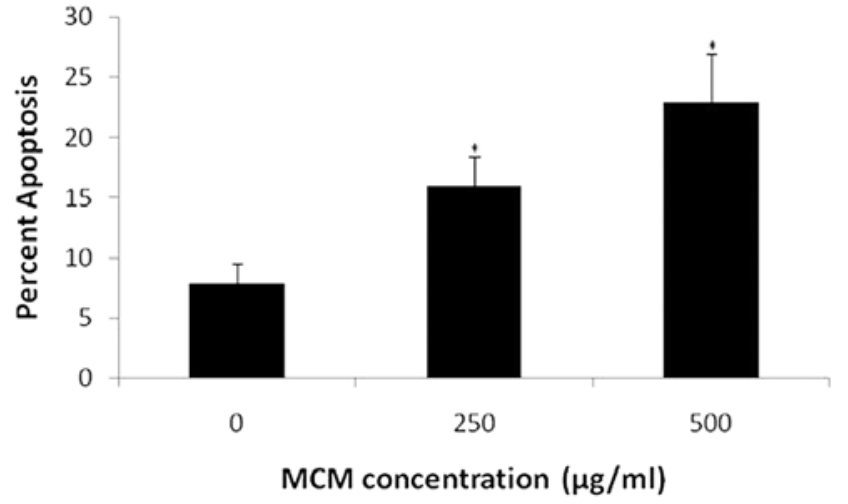

Figure 2. Apoptosis of LNCaP cells post-treatment with MCM examined by Giemsa stain. Tumor cells were cultured with MCM at a concentration of $500 \mu \mathrm{g} / \mathrm{ml}$ for 3 days. Cell apoptosis was examined in Giemsa-stained preparations under light microscopy. Data represent the mean \pm SD of three experiments. ${ }^{*} \mathrm{P}<0.01$ relative to control.
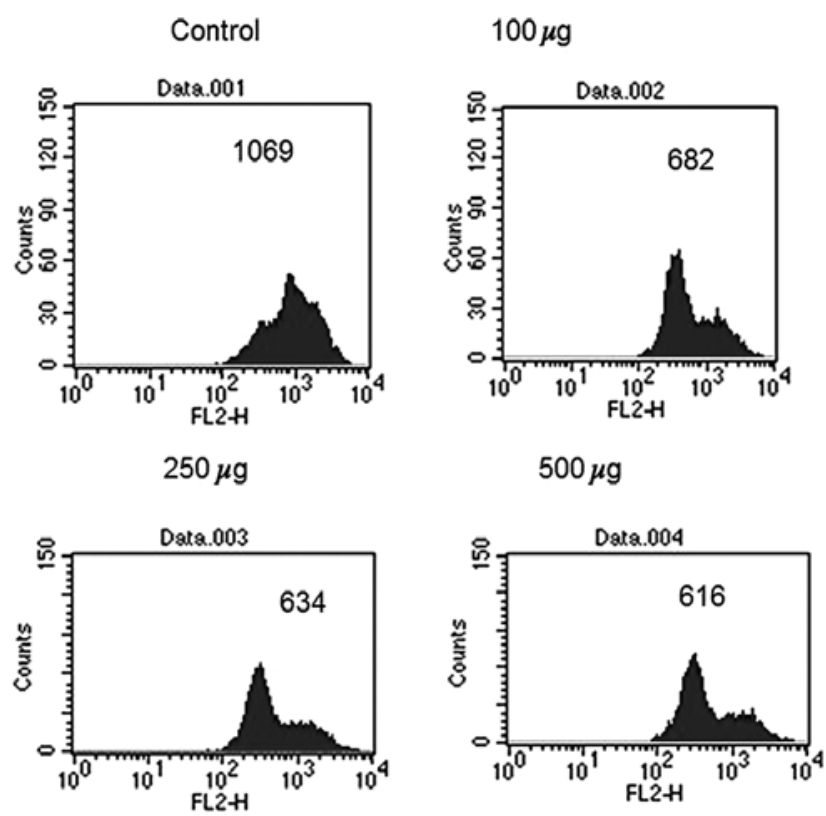

Figure 3. Effect of MCM on mitochondrial membrane potential of LNCaP tumor cells. Cancer cells were treated with MCM for $24 \mathrm{~h}$, then stained with TMRE and analyzed using flow cytometry. The numbers in the histogram represent Mean Fluorescence Channel Number.

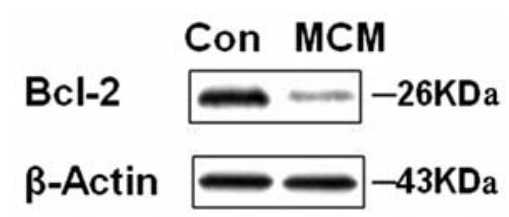

Figure 4. Effect of MCM on anti-apoptotic (Bcl-2) protein levels in LNCaP tumor cells. Cancer cell lysates were prepared and the expression of Bcl-2 protein was examined as described in Materials and methods. A representative blot from three separate experiments with identical results. Con, control, untreated cells; MCM, cells treated with $1000 \mu \mathrm{g} / \mathrm{ml} \mathrm{MCM}$.

changes in MMP. This permeabilization results in the release of pro-apoptotic factors into the cytosol and subsequent initiation of apoptosis $(13,14)$. The anti-apoptotic protein 
Bcl-2 is localized to the mitochondrial inner membrane and appears to play an important role in the maintenance of the MMP. Western blot analysis showed that treatment of cancer cells with MCM for 3 days resulted in significant downregulation of $\mathrm{Bcl}-2(\mathrm{P}<0.001)$ as compared to control untreated cells. Within the mitochondria are apoptogenic factors (cytochrome c, Smac/DIABLO, Omi) that if released activate the executioners of apoptosis, the caspases. Bcl-2 blocks the release of these apoptogenic factors. Down-regulation of Bcl-2 results in an increase in the release of caspases and other factors that induce apoptosis. In our recent study, we also showed that MCM has an apoptotic effect toward human metastatic breast cancer MDA-MB-231 cells and by a similar mechanism that involves down-regulation of Bcl-2.

MCM is isolated from the Orai-Oki Sea in the Ibaraji Prefecture, Japan, which contains the greatest concentration of plankton in the world. One ton of sea water produces $1 \mathrm{~kg}$ of sodium chloride-free MCM. Chemical analysis of the ingredients in sodium chloride-free MCM was conducted, and no harmful trace elements were detected. This analysis identified mineral and trace elements such as ferrate $(\mathrm{Fe})$, copper $(\mathrm{Cu})$, chromium-III (Cr-III), manganese $(\mathrm{Mn})$, zinc (Zn) and selenium (Se) in MCM. Each of these trace elements plays an essential biological role in humans and many exert an apoptotic effect against cancer. For example, $\mathrm{Cu}^{2+}$ plays an important physiological role whose homeostasis is tightly regulated. Disruption of $\mathrm{Cu}^{2+}$ homeostasis has been linked to several serious disorders, including cancer (15-17). The link between cancer and copper homeostasis has been bolstered by the discovery that $\mathrm{Cu}^{2+}$ treatment can inhibit neoplastic growth and increase survival in rat and mouse models of cancer (18). Increased uptake of other trace elements, such as $\mathrm{Se}$ and $\mathrm{Zn}$, has been suggested to decrease the incidence of cancer $(19,20)$. In addition, proteins containing trace elements such as $\mathrm{Se}, \mathrm{Cu}, \mathrm{Mn}$ and $\mathrm{Zn}$ have been identified in the prostate and are proposed to function in apoptosis and redox processes (21). It is not clear whether the observed increased apoptotic effect by MCM against $\mathrm{LNCaP}$ cells could be attributed to several, rather than a single one of the above- mentioned antioxidant minerals of MCM and further investigation in this area is needed to identify the contributing factors.

Several previous studies have also characterized the apoptotic effect that several trace elements have in cancer cells. For example, zinc sulfate was shown to induce apoptosis in HEP-2 cancer cells in vitro through disruption of mitochondrial membrane potential (22). In addition, Se induces apoptosis through caspase-independent pathways in cervical cancer cells (23). Natural organoselenium compounds have been shown to induce apoptosis and $\mathrm{S}$ phase arrest in MDA-MB-231 cells (24) and target Protein Kinase C, inhibiting its activity and thus interfering with the action of tumor promoters (25).

Results of this study revealed that $\mathrm{LNCaP}$ cells are very sensitive to the apoptotic effect by MCM. Cancer treatment with greater specificity for cancer cells and less toxicity for normal cells are needed. Discovery of a variety of therapeutic agents with less toxicity will lead to more effective therapies toward specific tumors. MCM, a natural product, could be used as a selective apoptotic-inducer for certain types of cancer, such as breast and prostate cancer. On the other hand,
MCM showed no negative effect on the proliferation of peripheral blood mononuclear cells (9), indicating it has low toxicity toward normal cells.

Immunological stimulation is currently receiving attention as a major treatment modality in the management of cancer patients (26-28). Several types of immune cells, such as cytotoxic T lymphocytes (CTL) and natural killer (NK) cells have demonstrated anti-cancer activity and may represent a promising cell therapy for the treatment of prostate cancer. However, prostate cancer is able to evade CTL immune surveillance through frequent loss of MHC class I and II expression in cancer cells and tissues (29-33), indicating that attempts to activate $\mathrm{T}$ cells may not be a successful strategy for the treatment of prostate cancer. On the other hand, many attempts were made to enhance activity of NK cells and expand their population, which are suppressed in prostate cancer patients $(34,35)$. These enhanced NK cells can then be used as effector cells for the treatment of prostate cancer (36-39). It is of great interest that MCM is a potent biological response modifier (BRM) that has the ability to enhance human NK cell activity in vivo and in vitro (9). Moreover, MCM was found to significantly increase interferon (IFN- $\gamma$ ) production (9), another important component of anti-cancer activity. Taken together, our data indicate that MCM possess anti-tumor activity and immunomodulatory properties and suggest its use as a new potent anti-cancer agent.

\section{References}

1. Ostrander EA and Johannesson B: Prostate cancer susceptibility loci: finding the genes. Adv Exp Med Biol 617: 179-190, 2008.

2. Sun J, Turner A, Xu J, Grönberg H and Isaacs W: Genetic variability in inflammation pathways and prostate cancer risk. Urol Oncol 25: 250-259, 2007.

3. Marty M, Mignot L, Gisselbrecht G, Morvan F, Gorins A and Boiron M: Teratogenic and mutagenic risks of radiotherapy: when and how to prescribe contraception. Contracept Fertil Sex 13: 181-186, 1985 .

4. Mills KH, Greally JF, Temperley IJ and Mullins GM: Haematological and immune suppressive effects of total body irradiation in the rat. Ir J Med Sci 149: 201-208, 1980.

5. Sanderson BJ, Ferguson LR and Denny WA: Mutagenic and carcinogenic properties of platinum-based anticancer drugs. Mutat Res 355: 59-70, 1996.

6. Santin AD, Hermonat PL, Ravaggi A, Bellone S, Roman J, Pecorelli S, Cannon M and Parham GP: Effects of concurrent cisplatinum administration during radiotherapy $v s$. radiotherapy alone on the immune function of patients with cancer of the uterine cervix. Int J Radiat Oncol Biol Phys 48: 997-1006, 2000.

7. Klotz L: Maximal androgen blockade for advanced prostate cancer. Best Pract Res Clin Endocrinol Metab 22: 331-340, 2008.

8. Ghoneum M and Gollapudi S: Marina crystal minerals (MCM) induce apoptosis of human metastatic breast cancer MDA-MB231 cells in vitro. In: Anticancer drugs: Design, Delivery, and Pharmacology. Nova Science Publishers, Inc. New York, 2008.

9. Ghoneum $\mathrm{M}$ and Ogura T: Immunomodulation of human NK cell activity by marina crystal minerals (MCM), a crystallized mixture of minerals and trace elements from sea water. Nutr Res 19: $1287-1298,1999$.

10. Ghoneum M and Gollapudi S: Synergistic role of arabinoxylan rice bran (MGN-3/Biobran) in S. cerevisiae-induced apoptosis of monolayer breast cancer MCF-7 cells. Anticancer Res 25: 4187-4196, 2005.

11. Ghoneum M, Hamilton J, Brown J and Gollapudi S: Human squamous cell carcinoma of the tongue and colon undergoes apoptosis upon phagocytosis of Saccharomyces cerevisiae, the baker's yeast, in vitro. Anticancer Res 25: 981-989, 2005. 
12. Ghoneum M, Seto Y, Sato S, Ghoneum A, Braga M and Gollapudi S: Gross thymic extract, Thymax, induces apoptosis in human breast cancer cells in vitro through the mitochondrial pathway. Anticancer Res 28: 1603-1610, 2008.

13. Hengartner MO: The biochemistry of apoptosis. Nature 407: 770-776, 2000

14. Nunez G and Clarke MF: The Bcl-2 family of proteins: regulators of cell death and survival. Trends Cell Biol 4: 399-403, 1994.

15. Goodman VL, Brewer GJ and Merajver SD: Control of copper status for cancer therapy. Curr Cancer Drug Targets 5: 543-549, 2005.

16. Sigurdsson EM, Brown DR, Alim MA, et al: Copper chelation delays the onset of prion disease. J Biol Chem 278: 46199-46202, 2003.

17. Gnjec A, Fonte JA, Atwood C and Martins RN: Transition metal chelator therapy - a potential treatment for Alzheimer's disease? Front Biosci 7: 1016-1023, 2002.

18. Syrkin AB and Chlenova EL: Antidotal and antineoplastic properties of copper sulfate. Biull Eksp Biol Med 105: 477-479, 1988

19. Schwartz LH, Urban T and Hercberg S: Antioxidant minerals and vitamins. Role in cancer prevention. Presse Med 23: 1826-1830, 1994

20. Watson RR: Immunological enhancement by fat-soluble vitamins, minerals, and trace metals: a factor in cancer prevention. Cancer Detect Prev 9: 67-77, 1986.

21. Grbavac I, Wolf C, Wenda N, et al: Metal-containing proteins in the apoptosis and redox processes in the rat prostate and human prostate cells. Ann NY Acad Sci 1090: 113-119, 2006.

22. Rudolf $\mathrm{E}$, Rudolf $\mathrm{K}$ and Cervinka M: Zinc induced apoptosis in HEP-2 cancer cells: the role of oxidative stress and mitochondria. Biofactors 23: 107-120, 2005.

23. Rudolf E, Rudolf K and Cervinka M: Selenium activates p53 and $\mathrm{p} 38$ pathways and induces caspase-independent cell death in cervical cancer cells. Cell Biol Toxicol 24: 123-141, 2008.

24. Wang J, Jiao NL and Zheng J: Effects of Se-methylselenocysteine on biological behavior of and matrix metalloproteinase-2 expression in human breast cancer MDA-MB-231 cells. Chin J Cancer (Ai Zheng) 27: 119-125, 2008.

25. Gopalakrishna R and Jaken S: Protein kinase $\mathrm{C}$ signaling and oxidative stress. Free Radic Biol Med 28: 1349-1361, 2000.

26. Pross HF and Lotzová EL: Role of natural killer cells in cancer. Nat Immun 12: 279-292, 1993
27. Herberman RB: Natural killer cells and tumor immunity. Sury Immunol Res 2: 306-308, 1983.

28. Robertson MJ and Ritz J: Biology and clinical relevance of human natural killer cells. Blood 76: 2421-2438, 1990.

29. Blades RA, Keating PJ, McWilliam LJ, et al: Loss of HLA class I expression in prostate cancer: implications for immunotherapy. Urology 46: 681-687, 1995.

30. Sanda MG, Restifo NP, Walsh JC, et al: Molecular characterization of defective antigen processing in human prostate cancer. J Natl Cancer Inst 87: 280-285, 1995.

31. Bander NH, Yao D, Liu H, et al: MHC class I and II expression in prostate carcinoma and modulation by interferonalpha and -gamma. Prostate 33: 233-239, 1997.

32. Lu QL, Abel P, Mitchell S, et al: Decreased HLA-A expression in prostate cancer is associated with normal allele dosage in the majority of cases. J Pathol 190: 169-176, 2000.

33. Townsend $\mathrm{A}$ and Bodmer $\mathrm{H}$ : Antigen recognition by class Irestricted T lymphocytes. Annu Rev Immunol 7: 601-624, 1989.

34. Lahat N, Alexander B, Levin DR and Moskovitz B: The relationship between clinical stage, natural killer activity and related immunological parameters in adenocarcinoma of the prostate. Cancer Immunol Immunother 28: 208-212, 1989.

35. Kastelan M, Kraljic I and Tarle M: NK cell activity in treated prostate cancer patients as a probe for circulating tumor cells: Hormone regulatory effects in vivo. Prostate 21: 111-120, 1992.

36. Zhu D, Corral LG, Fleming YW and Stein B: Immunomodulatory drugs Revlimid (lenalidomide) and CC-4047 induce apoptosis of both hematological and solid tumor cells through NK cell activation. Cancer Immunol Immunother 57: 1849-1859, 2008.

37. Raja Gabaglia C, Diaz de Durana Y, Graham FL, et al: Attenuation of the glucocorticoid response during Ad5IL-12 adenovirus vector treatment enhances natural killer cell-mediated killing of MHC class I-negative LNCaP prostate tumors. Cancer Res 67: 2290-2297, 2007.

38. Esplugues E, Vega-Ramos J, Cartoixà D, et al: Induction of tumor NK-cell immunity by anti-CD69 antibody therapy. Blood 105: 4399-4406, 2005

39. Oikawa T, Kawai K, Ishiwata I, et al: Induction of potent antitumour natural-killer cells from peripheral blood of patients with advanced prostate cancer. BJU Int 92: 1009-1015, 2003. 